\title{
Journal of Applied Aquaculture
}

\section{Depletion of stored nutrients during fasting in Nile tilapia (Oreochromis niloticus) juveniles}

\section{Caroline Nebo, Rodrigo Yukihiro Gimbo, Juliana Tomomi Kojima, Ken Overturf, Maeli Dal-Pai-Silva \& Maria Célia Portella}

To cite this article: Caroline Nebo, Rodrigo Yukihiro Gimbo, Juliana Tomomi Kojima, Ken Overturf, Maeli Dal-Pai-Silva \& Maria Célia Portella (2018) Depletion of stored nutrients during fasting in Nile tilapia (Oreochromis niloticus) juveniles, Journal of Applied Aquaculture, 30:2, 157-173, DOI: 10.1080/10454438.2017.1420516

To link to this article: https://doi.org/10.1080/10454438.2017.1420516

Accepted author version posted online: 26

Dec 2017.

Published online: 03 Jan 2018.

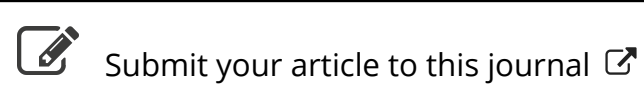

Џ Article views: 64

View Crossmark data ¿ 


\title{
Depletion of stored nutrients during fasting in Nile tilapia (Oreochromis niloticus) juveniles
}

\author{
Caroline Nebo a, Rodrigo Yukihiro Gimbo a, Juliana Tomomi Kojima ${ }^{a}$, Ken Overturf ${ }^{b}$, \\ Maeli Dal-Pai-Silva ${ }^{a}$, and Maria Célia Portella ${ }^{c}$ \\ aFaculdade de Ciências Agrárias e Veterinárias, UNESP Universidade Estadual Paulista, Jaboticabal, São \\ Paulo, Brazil; bUSDA-ARS, Hagerman Fish Culture Experiment Station, Hagerman, Idaho, USA; 'Centro \\ de Aquicultura (Caunesp), UNESP Universidade Estadual Paulista, Jaboticabal, São Paulo, Brazil
}

\begin{abstract}
We evaluated growth performance and metabolic responses in Nile tilapia (Oreochromic niloticus) juveniles (30.2 $\pm 0.9 \mathrm{~g})$ subjected to 1 (F1), 2 (F2), or 3 weeks (F3) of fasting and then refed for 10 weeks (10WR) compared to controls (FC), which were fed for the full 13-week trial. Weight gain and specific growth rate (SGR) during fasting were lower in all treatments compared to the FC. However, during refeeding, feed intake/body mass and SGR increased in F1, F2, and F3, inducing partial compensatory growth. The hepatosomatic index (HSI), visceral fat index (VFI), liver glycogen (LG), and carcass lipid levels dropped in all fasted fish compared to FC $(P<0.05)$, showing a depletion of stored nutrients such as fat and LG. Along with LG, fat reserves were mobilized during fasting to maintain basal metabolism and survival, but these energy constituents returned to control levels at 10WR, at which time HSI was higher in all refed fish compared to FC. Additionally, the variables VFI, LG, and lipid in carcass increased in all refed fish, equaling those of FC at 10WR. The results showed that, in contrast with other protocols that used smaller tilapia juveniles, the feeding strategies utilized for Nile tilapia juveniles in this study ( 1 to 3 weeks of fasting and 10WR) were able to induce only partial compensatory growth. It can be concluded that in situations that require complete food restriction in juvenile Nile tilapia $(30 \mathrm{~g})$, an acceptable strategy is to limit the period of fasting to 1 week or less to minimize losses and to achieve partial compensatory growth.
\end{abstract}

\section{KEYWORDS}

Compensatory growth; nutrient storage

\section{Introduction}

Tilapia farming is increasing worldwide in response to the intensifying demand for this fish species and the global need to broaden the sources of animal-derived protein for human consumption (Fitzsimmons, Martínez-García, and GonzálezAlanis 2011). Indeed, in 2012, farmed tilapia exceeded 3.2 million tons per annum, surpassing the salmon and catfish industries (Food and Agriculture Organization of the United Nations [FAO] 2012).

CONTACT Ken Overturf Ken.Overturf@ars.usda.gov @ USDA-ARS, Hagerman Fish Culture Experiment Station, Hagerman, ID 83332, USA.

Color versions of one or more of the figures in the article can be found online at www.tandfonline.com/wjaa 
As part of an effort to improve tilapia meat quality and farm productivity, researchers exploring alternative feeding strategies have studied the effects of fasting on compensatory growth, which has contributed to the understanding of how nutritional energy is mobilized within the fish to maintain vital processes and survival. Furthermore, fasting protocols in fish are also used to improve product quality by reducing muscle lipid content and the effects of stress during starvation (Antonopoulou et al. 2013; Grigorakis and Alexis 2005; Zhang et al. 2008). Some studies have analyzed fasting and refeeding effects on tilapia at different growth phases and found that compensatory growth varied from partial to full depending on the growth phase and time off feed (Abdel-Hakim et al. 2009; Breves et al. 2014; Nebo et al. 2013; Wang et al. 2000; Wang, Qin, and Han 2009). A study with hybrid tilapia (4.3 g) (Oreochromis mossambicus x O. niloticus) reared in seawater found total compensatory growth after 1 week of fasting followed by refeeding for 4 weeks (Wang et al. 2000). However, only partial compensatory growth was obtained when Nile tilapia $(O$. niloticus) juveniles $(6.6 \mathrm{~g})$ were subjected to cyclical feed deprivation ( 1 to $4 \mathrm{~d}$ ) and refeeding ( 2 to $8 \mathrm{~d}$ ) (Wang, Qin, and Han 2009). Against this background, we conjectured that a modified protocol could provide better compensatory growth results for farming of Nile tilapia (O. niloticus). Indeed, differences in compensatory growth may be related to different experimental protocols, environmental conditions, or physiological conditions of fish.

The metabolic rate of fish, as well as that of other ectotherms, may decrease during fasting (Drew et al. 2008; Jobling 1980; Wang, Hung, and Randal 2006). Fish metabolism is largely based on lipids and proteins, with lipid storage in the liver, viscera, and muscle. However, lipid distribution between these body components varies among species (Jobling and Johansen 1999; Love 1970). During fasting, vital processes are maintained using endogenous energy stores, and fasting induces changes in the storage reserves, particularly those of lipids (Ali, Nicieza, and Wooton 2003; Navarro and Gutiérrez 1995; Nicieza and Álvarez 2009). Gaylord and Gatlin (2001) found that channel catfish (Ictalurus punctatus) juveniles modulated visceral organ size and composition in response to feed deprivation and refeeding. Their energy stores in the liver and visceral fat were mobilized to maintain basic metabolic functions, showing that during fasting, lipids are consumed earlier than other body components.

Here we examined the effect of different periods of fasting and refeeding on the dynamics of growth depression and depletion of energy sources in Nile tilapia (O. niloticus) juveniles.

\section{Material and methods}

\section{Experimental design}

Nile tilapia (O. niloticus) juveniles of the Thai-Chitralada strain $(30.2 \pm 0.9 \mathrm{~g})$ were obtained from a commercial farm (Royal Fish, Itupeva-São Paulo, 
Brazil) and acclimated for $15 \mathrm{~d}$ at the experimental facilities. A total of 1,120 fish was stored in thirty-two 150-L tanks with constant water flow and aeration. The experiment lasted 13 weeks, and a fixed period of 10 weeks of refeeding was maintained for all fasting treatments. Fish were randomly distributed into four experimental treatments with eight replicates: FC: fed control, fish were fed continuously during 13 weeks; F1: one week of fasting and 10 weeks of refeeding; F2: two weeks of fasting and 10 weeks refeeding; F3: three weeks of fasting and 10 weeks refeeding. At the end of each week of fasting (1WF, 2WF, 3WF) and at the end of refeeding (1 week refeeding [1WR], 2 weeks refeeding [2WR], 6 weeks refeeding [6WR], and 10 weeks refeeding $[10 \mathrm{WR}])$ samples were taken. Fish were fed to apparent satiation with an extruded commercial diet (crude protein $320 \mathrm{~g} / \mathrm{kg}$, moisture $80 \mathrm{~g} / \mathrm{kg}$, lipids $65 \mathrm{~g} / \mathrm{kg}$, ash $100 \mathrm{~g} / \mathrm{kg}$-information provided by the food company: Guabi, Sales de Oliveira-São Paulo, Brazil) three times per day (09:00, 14:00, and 17:00). Water variables were monitored daily for temperature $\left(30.1 \pm 0.32^{\circ} \mathrm{C}\right), \mathrm{pH}(7.89 \pm 0.14)$, and dissolved oxygen $(4.74 \pm 0.86 \mathrm{mg} / \mathrm{L})$ and weekly for total ammonia $(0.1 \pm 0.04 \mathrm{mg} / \mathrm{L})$, nitrite $(0.03 \pm 0.02 \mathrm{mg} / \mathrm{L})$, and nitrate $(0.15 \pm 0.03 \mathrm{mg} / \mathrm{L})$.

\section{Biometric and biochemical analysis}

At the beginning of the experiment, all fish were anesthetized with benzocaine $(0.1 \mathrm{~g} / \mathrm{L})$, individually weighed, and randomly distributed to each experimental treatment (32 fish/tank). At the end of each week of fasting (1WF, 2WF, 3WF) and at the end of refeeding (1-week refeeding [1WR], 2week refeeding [2WR], 6-week refeeding [6WR], and 10-week refeeding $[10 \mathrm{WR}])$, fish were anesthetized with benzocaine $(0.1 \mathrm{~g} / \mathrm{L})$ and individually weighed to evaluate body mass, specific growth rate, and feed intake/body mass. Following blood sample collection, fish were euthanized (benzocaine $0.4 \mathrm{~g} / \mathrm{L}$ ), and tissue samples (liver, muscle and visceral fat) were taken from eight fish per treatment, and another set of fish was sampled for carcass analysis (eight fish/treatment), totaling 16 fish/treatment ( 2 fish/tank) for each point of analysis (1WF, $2 \mathrm{WF}, 3 \mathrm{WF}$, and $10 \mathrm{WR})$.

The number of fish in all treatments was adjusted (taken out randomly to maintain the same density in the tanks) after sampling. The parameters evaluated were as follows:

Weight gain $(\mathrm{WG})(\mathrm{g})=$ final body mass $(\mathrm{BM})-$ initial $\mathrm{BM}$

Specific growth rate $(\mathrm{SGR})(\%$ day -1$)=[(\operatorname{Ln}$ final BM $-\operatorname{Ln}$ initial $\mathrm{BM}) \times 100]$ /number of days between the biometric measurements

Feed intake $(\mathrm{FI})$ in relation to $\mathrm{BM}(\%)=[\mathrm{FI}(\mathrm{g}) / \mathrm{BM}(\mathrm{g})] \times 100$ 
Hepatosomatic index (HSI, \%) and visceral fat index (VFI, \%) $=[$ tissue weight $(\mathrm{g}) /$ total BM $(\mathrm{g})] \times 100$

To investigate compensatory responses, we analyzed feed intake during the first three days of refeeding, and survival rate was evaluated at the end of the experiment.

\section{Carcass proximate composition}

Whole fish carcass samples were collected $(n=8$ fish $)$ and frozen at $-20^{\circ} \mathrm{C}$. Proximate carcass composition was determined in dry matter. Carcass crude protein content $(\mathrm{N} \times$ 6.25) was measured using the Dumas method with a nitrogen analyzer (LECO FP-528), lipids by ether extraction using Soxhlet extraction, ash by combustion in a muffle furnace at $600^{\circ} \mathrm{C}$, and moisture by drying to a constant weight at $105^{\circ} \mathrm{C}$. Analyses were performed following Association of Analytical Chemists procedures (AOAC 2000).

\section{Blood analyses}

Blood samples $(n=8)$ were taken from the caudal vessel of each fish. Blood with anticoagulant (Glistab, Labtest, São Paulo, Brazil, code 29) was used to determine glucose and triglyceride levels (Labtest, São Paulo, Brazil, codes 84 and 87 respectively). Serum was stored at $-20^{\circ} \mathrm{C}$ for further determination of cholesterol, total proteins (Labtest, São Paulo, Brazil, codes 76 and 99) and cortisol (DRG ${ }^{\circledast}$ Cortisol ELISA, EIA-1887). All assays were performed according to the manufacturer's instructions.

\section{Liver and muscle analyses}

Liver and dorsal muscle were collected from the same fish and stored at -20 ${ }^{\circ} \mathrm{C}$ for further determination of lipid and glycogen levels. Liver glycogen was measured by lysis in amyloglycosidase after extraction with perchloric acid (7\%) (Moon, Foster, and Plisetskaya 1989). Liver and muscle lipids were determined after extraction in a chloroform and methanol solution (2:1) following Bligh and Dyer (1959), and muscle protein was determined according to Bradford (1976).

The study was approved by the Ethics Committee on Animal Use of the Faculdade de Ciências Agrárias e Veterinárias, UNESP Universidade Estadual Paulista. (CEUA/FCAV/UNESP, 009436/11).

\section{Statistical analysis}

The results obtained for each parameter were expressed as the mean \pm SEM for each experimental treatment. All parameters were evaluated and compared between groups (FC, 1WF, 2WF, and $3 \mathrm{WF}$ ) at the end of 1, 2, and 3 weeks of 
fasting, and after 1, 2, 6, and 10 weeks of refeeding (1WR, 2WR, 6WR, and 10WR). All data were tested for normality and homogeneity of variances by the Cramér-von Mises test and Brown-Forsythe's test respectively and then submitted to a one-way ANOVA. When these tests showed significance $(\mathrm{P}<0.05)$, means were compared using Tukey's test. Logarithmic transformations (natural logarithm) were applied before ANOVA to original data of growth performance (weight gain and specific growth rate), carcass composition (lipid), biochemical parameters (cholesterol, total protein, and cortisol), hepatosomatic index, and visceral fat index in the case of unequal variances and/or normality. A significance level of $\alpha=0.05$ and SAS Software Version 9.2 (2009) were used for all statistical analyses.

\section{Results}

\section{Decline in performance after fasting and recovery after refeeding of Nile tilapia}

Survival rate of Nile tilapia juveniles was higher than $84 \%$ in the FC, F1, and F2 treatments, whereas in the F3 it was approximately $79 \%$. However, these differences were not significant.

WG increased during refeeding periods (1WR, 2WR, 6WR, and 10WR), but it was lower in all refed fish than in control fish. At $1 \mathrm{WR}, \mathrm{WG}$ in refed fish from F1 was significantly higher compared to the F3 treatment. At 2WR, WG did not differ in all refed fish. However, at 6WR, WG was higher in fish from F3 compared to the F1 and F2 treatments. After 10WR, WG in fish from F1 was significantly higher compared to the F2 and F3 treatments (Table 1).

SGR was lower in all fasted fish compared to control fish, and it varied among the fasting treatments. At 1WR, SGR in fish from F1 and F2 was higher than it was in the FC treatment. At 2WR, SGR in fish from F1 and F3 did not differ from control values, whereas in the F2 it was lower compared to the FC treatment. However, at 6WR, SGR was higher in all fasted fish than in the FC treatment, and at 10 WR, SGR was lower in F2 and F3 fish compared to the FC treatment (Table 1).

During the first three days of refeeding, fasted fish did not show higher feed intake/body mass than control fish. During this time feed intake for F1 was significantly lower $(\mathrm{P}<0.01)$ than in the control on the first refeeding day, while at the other refeeding periods it was similar to level of the FC treatment. Feed intake of fish from the F2 treatment did not differ in comparison to the FC treatment at the first day of refeeding and at 10WR but was higher than the control at 2WR $(\mathrm{P}<0.001)$ and $6 \mathrm{WR}(\mathrm{P}<0.001)$. Fish fasted for the longest time (F3) showed increased feed intake during refeeding. At one week of refeeding, feed intake in F3 was lower $(\mathrm{P}<0.001)$ 


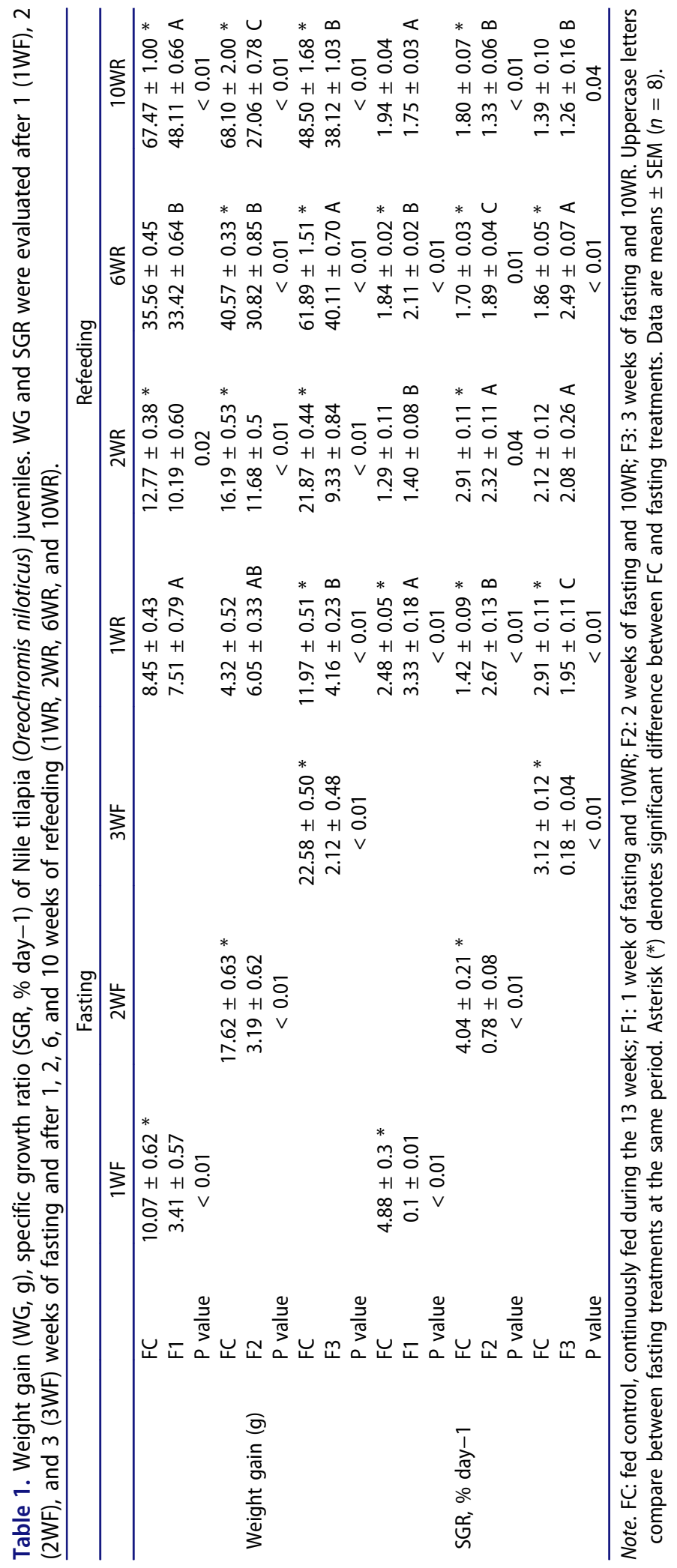


than in FC, but at $2 \mathrm{WR}$ it was similar to the control, and at $6 \mathrm{WR}$ and $10 \mathrm{WR}$ it was significantly higher. When comparing the feed intake/body mass of fish fasted for different periods (F1, F2, and F3), we observed a trend of higher intake in the F1 treatment during the first three days of refeeding, but this tendency did not persist into the following weeks (Figure 1).

\section{Lipids as the primary energy source during fasting}

Proximate composition analyses showed significant carcass lipid reduction $(\mathrm{P}<0.001)$ in the F1, F2, and F3 treatments during the fasting periods. However, after 10WR, body lipid percentage was either higher (in F3) or equal to (in F1 and F2) that of the FC treatment (Figure 2a). There was no difference in the percentage of carcass crude protein throughout the experiment among all treatments (Figure $2 \mathrm{~b}$ ). Carcass ash percentage was higher in the F2 $(\mathrm{P}<0.001)$ and F3 $(\mathrm{P}<0.05)$ treatments compared to the FC treatment. Nonetheless, after 10WR, no differences were observed among the treatments (Figure 2c). Moisture percentage was higher in F3 than in FC after fasting $(\mathrm{P}<0.001)$ and lower after 10WR (Figure $2 \mathrm{~d})$.

\section{Blood biochemical parameters}

Serum glucose levels in all fasted fish were similar to those of control fish at the end of each fasting and refeeding period. However, glucose was

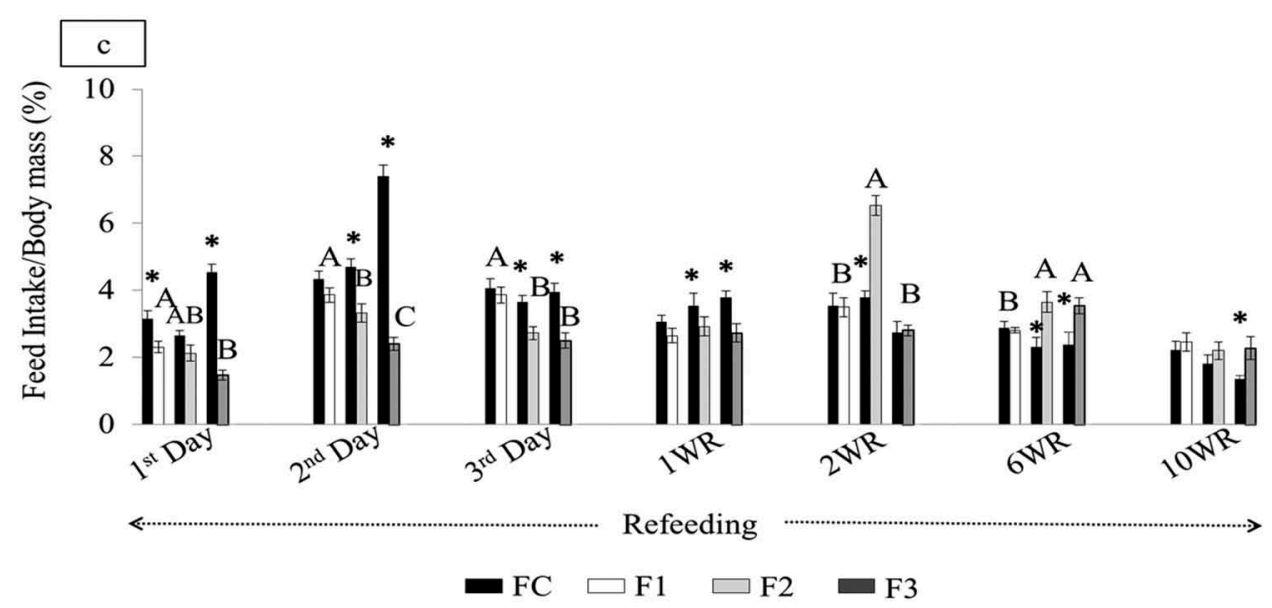

Figure 1. Feed intake/body mass (FI/BM, \%) of Nile tilapia (Oreochromis niloticus) juveniles measured at the first, second, and third days of refeeding and after 1WR, 2WR, 6WR, and 10WR. FC: fed control, continuously fed during the 13 weeks; F1: one week of fasting and 10WR; F2: two weeks of fasting and 10WR; F3: three weeks of fasting and 10WR. Uppercase letters compare between fasting treatments. Asterisk $\left(^{*}\right)$ denotes significant differences $(P<0.05)$ between FC and fasting treatments. Data are means \pm SEM $(n=8)$. 

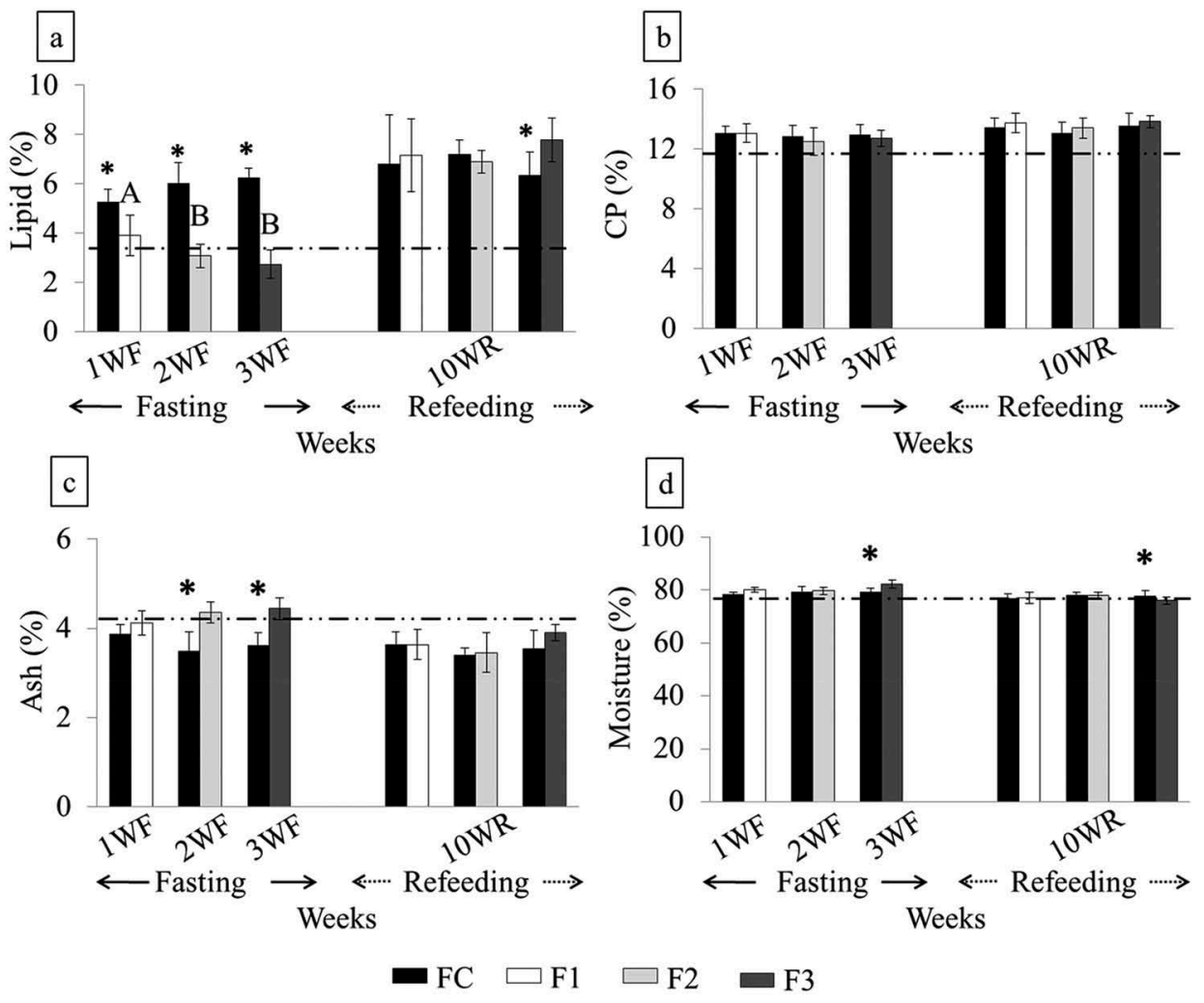

Figure 2. Lipids as the primary energy source during fasting of Nile tilapia (Oreochromis niloticus). Proximate composition (lipid, crude protein, ash, and moisture \%) after one (1WF), two (2WF), and three (3WF) weeks of fasting and 10 weeks of refeeding (10WR); FC: control, continuously fed during the 13 weeks; F1: one week of fasting and 10WR; F2: two weeks of fasting and 10WR; F3: three weeks of fasting and 10WR. Uppercase letters compare among fasted fish. Asterisk $\left(^{*}\right)$ denotes significant differences $(P<0.05)$ between $F C$ and fasting treatments. Data are means \pm SEM $(n=8)$. Dashed line shows initial values $(\%)$ at day 0 , which were: lipid $3.74 \pm 0.03$; crude protein $12.00 \pm 0.13$; ash $4.58 \pm 0.04$; and moisture $78.49 \pm 0.21$.

significantly higher in fish from the F3 treatment compared to the F1 and F2 treatments after fasting (Figure 3a).

Serum triglycerides after fasting were significantly lower $(\mathrm{P}<0.005)$, compared to the FC treatment, only in the F1 treatment. Among the fasting treatments, triglycerides were higher in F3 than in F1 fish. At the end of each refeeding period, no differences were found between FC and refed fish, but comparisons between the refed fish showed higher levels of plasma triglycerides in F1 and F3 $(\mathrm{P}<0.05)$ (Figure $3 \mathrm{~b})$.

Serum cholesterol levels did not differ between fasted and control fish at the end of each fasting and refeeding period. Nonetheless, cholesterol was 


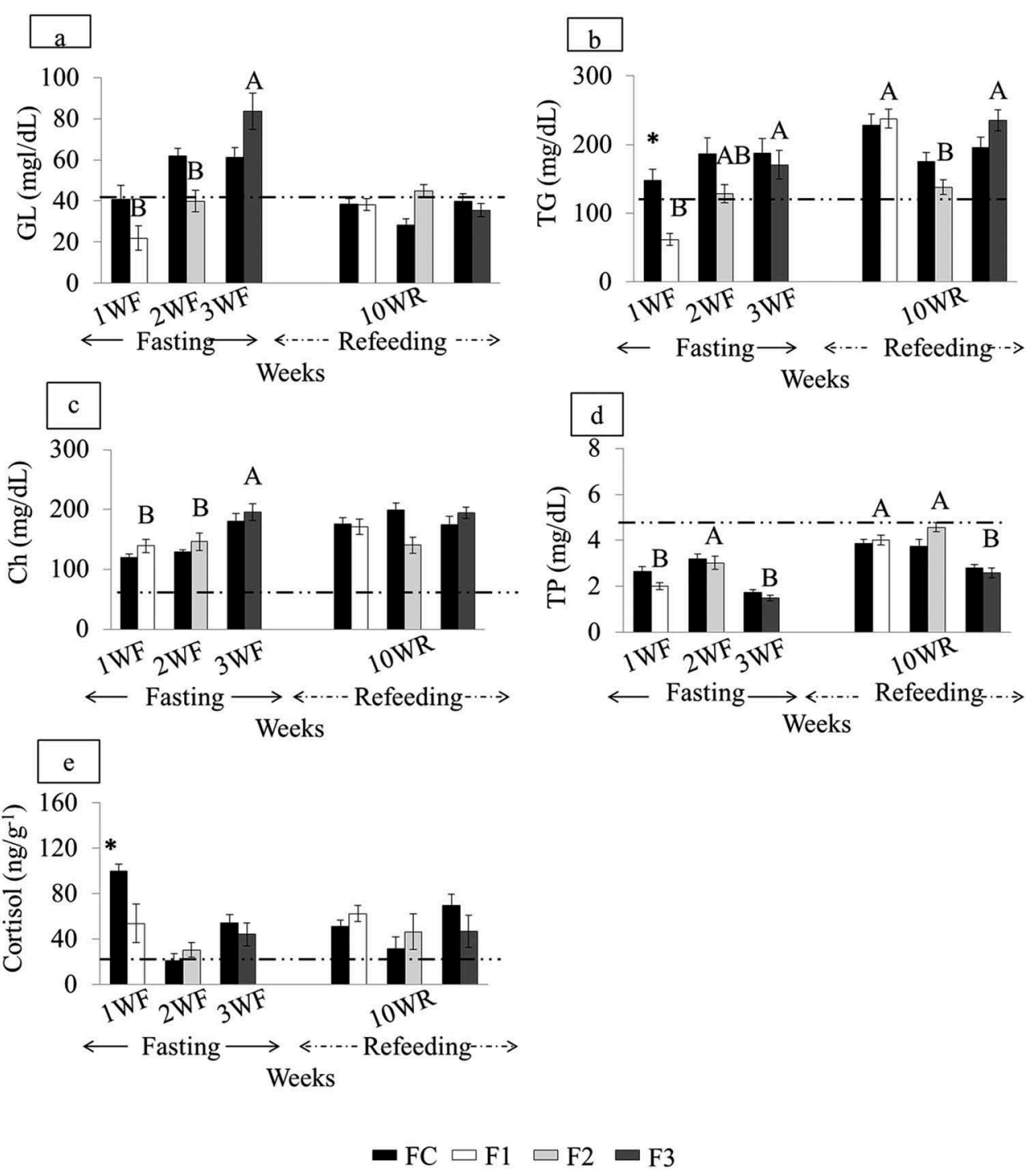

Figure 3. Changes in plasma glucose (GL), triglycerides (TG), serum cholesterol (Ch), total protein (TP), and cortisol levels of Nile tilapia (Oreochromis niloticus) juveniles after one (1WF), two (2WF), and three (3WF) weeks of fasting and 10 weeks of refeeding (10WR). FC: control, continuously fed during the 13 weeks; F1: one week of fasting and 10WR; F2: two weeks of fasting and 10WR; F3: three weeks of fasting and 10WR. Uppercase letters compare among fasted fish. Asterisk $(*)$ denotes significant differences $(P<0.05)$ between $F C$ and fasting treatments. Data are means \pm SEM $(n=8)$. Dashed line shows values at day 0 , which were: glucose $43.09 \pm 2.02$; triglycerides $135.50 \pm 10.26$; cholesterol $74.27 \pm 6.47$; total protein $5.19 \pm 0.28$; and cortisol $27.67 \pm 4.85$.

significantly higher in fish from F3 in comparison to the F1 and F2 treatments after fasting (Figure 3c).

Serum total protein did not differ between fasted and control fish at the end of each fasting and refeeding period. However, among the fasting treatments, total protein in the F2 treatment was higher than in the F1 and F3 
treatments. Moreover, after refeeding, total protein was higher in the F1 and F2 treatments than in the F3 treatment (Figure $3 \mathrm{~d}$ ).

At Day 0, the cortisol level was $27.67 \pm 4.85 \mathrm{ng} / \mathrm{g}$. During the fasting phase, cortisol was higher in control fish compared to those in the F1 treatment (Figure 3e).

\section{Decline in hepatosomatic index (HSI) and visceral fat index (VFI) after fasting and recovery after refeeding}

After fasting, HSI was significantly lower in fasted compared to control fish, while among the fasting treatments higher values were found in F1 and F2 compared to F3. However, after $10 \mathrm{WR}$, HSI in all refed treatments was higher than in the FC treatment $(\mathrm{P}<0.05)$, with no significant differences among the refed treatments (Figure 4a). VFI was significantly lower in the F2 and F3 treatments compared to the FC treatment after fasting $(\mathrm{P}<0.001)$ with no differences seen between fed groups or compared to the FC treatment (Figure 4b).

\section{Liver glycogen mobilization during fasting and reestablishment after refeeding}

Liver glycogen levels dropped significantly in all fasted fish. However, after 10WR, no differences were found between control and fasted fish $(\mathrm{P}>0.05)$. Indeed, after refeeding, the highest liver glycogen level was observed in the F3 treatment (Figure 4c). Liver lipid levels did not differ between control and fasted fish throughout the experiment $(\mathrm{P}>0.05)$ (Figure $4 \mathrm{~d}$ ).

Muscle lipid also did not differ between fasted and control fish during either the fasting or refeeding periods. However, after the end of refeeding, muscle lipid levels were higher in the F1 than in the F3 treatment (Figure 4e).

Muscle protein level during the fasting period was significantly higher in the F2 treatment compared to the control, while in refed fish muscle protein was higher in the F1 treatment, again in comparison to the control. Muscle protein level varied among fasted fish during fasting, being higher in F3 than in the other two treatments. However, after refeeding it was lower in F3 than in F1 and F2 (Figure 4f).

\section{Discussion}

In the wild, fasting is a situation that occurs in a fish's life due to food limitation, migration, and reproduction, among other factors. It also may occur in farming conditions as a consequence of poor water quality, pathogens, handling, transport, and temperature variations that can be stressors for 

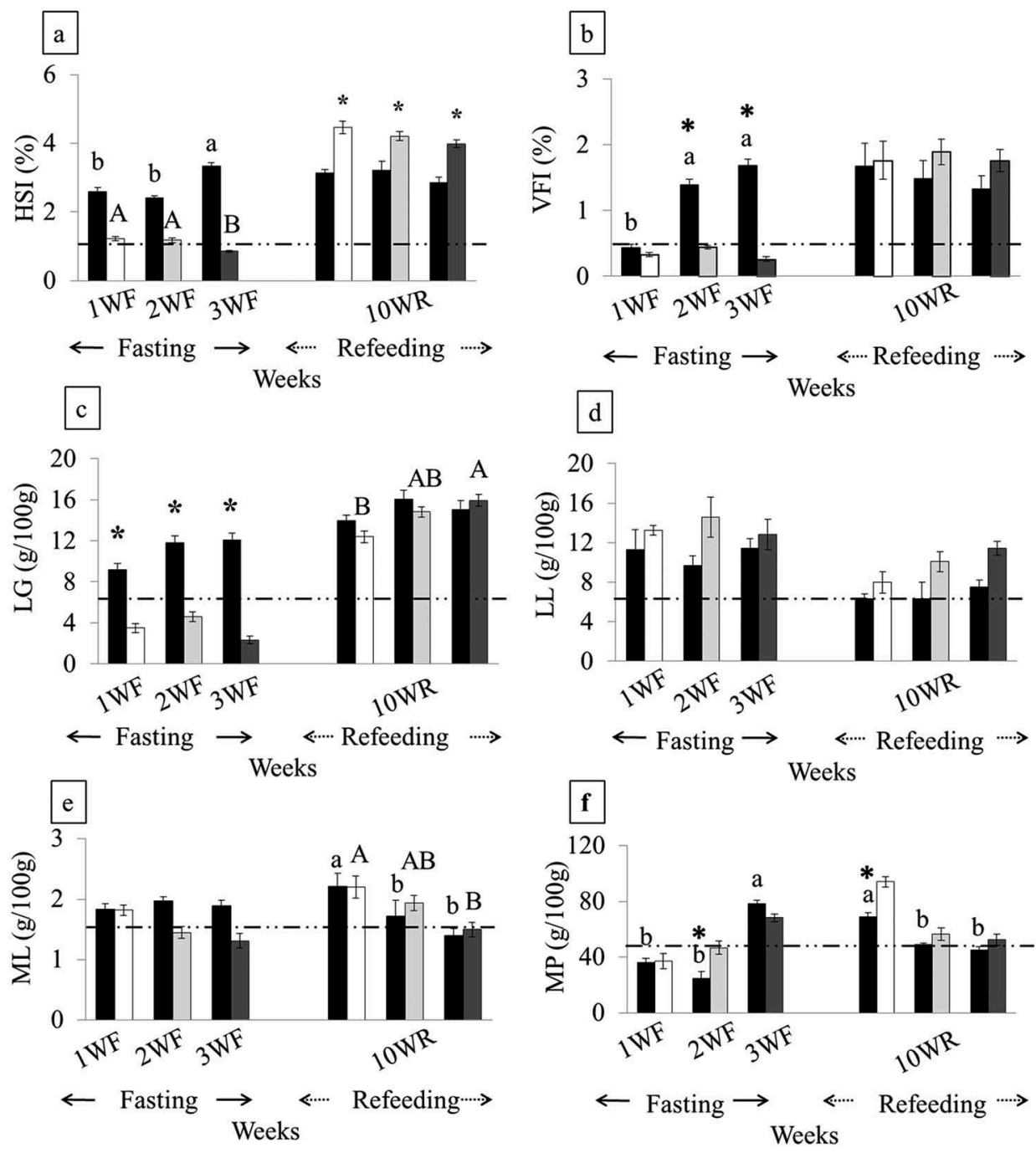

Figure 4. Changes in hepatosomatic index (HSI, liver weight/body mass, \%), visceral fat index (VFI, tissue weight/body mass, \%), liver glycogen (LG), liver lipid (LL), muscle lipid (ML), and muscle protein (MP) of Nile tilapia (Oreochromis niloticus) juveniles after 1 (1WF), 2 (2WF), and 3 (3WF) weeks of fasting and 10 weeks of refeeding (10WR); FC: control, continuously fed during the 13 weeks; F1: 1 week of fasting and 10WR; F2: 2 weeks of fasting and 10WR; F3: 3 weeks of fasting and 10WR. Uppercase letters compare among fasted fish. Asterisk $\left(^{*}\right)$ denotes significant differences $(\mathrm{P}<0.05)$ between $\mathrm{FC}$ and fasting treatments. Data are means \pm SEM $(n=8)$. Dashed line shows values at day 0 , which were: HSI $1.28 \pm 0.10$; VFI $0.38 \pm 0.06$; liver glycogen $6.99 \pm 0.53$; liver lipid $6.76 \pm 0.51$; muscle lipid $1.54 \pm 0.07$; and muscle protein $42.32 \pm 3.25$.

fish (Barton 2002; Won and Borsk 2013). However, after a period of fasting and the reestablishment of normal feeding conditions, fish may exhibit compensatory growth. Thus, the use of the fasting technique, which can modify muscle proximate composition and lipid content, is a strategy to improve fish meat quality and fish farm productivity (Grigorakis and Alexis 
2005; Zhang et al. 2008). In this study, we analyzed the dynamics of growth and mobilization of energy sources in Nile tilapia (O. niloticus) juveniles during different periods of fasting and after refeeding.

Tilapia fasted for 1 to 3 weeks weighed significantly less than full-fed controls, with a significant reduction in lipid content and an increase of moisture in the carcass observed. In Dentex dentex, weight loss after fasting was a result of energy mobilization from various body compartments to maintain important life processes (Pérez-Jiménez et al. 2012). In this study, fasting for 1 to 3 weeks reduced SGR and induced intense mobilization of energy sources to maintain necessary metabolic processes in Nile tilapia juveniles. This same result of decreased SGR was observed with hybrid tilapia (O. niloticus $\mathrm{x}$ O. aureus) juveniles (14.5 g) reared in freshwater with fasting cycles of 3 days per week for 4 months (Abdel-Hakim et al. 2009).

However, during refeeding, SGR in all fasted fish increased, suggesting recovered growth capacity and partial compensatory growth. Similarly, in other fasting and refeeding protocols with Mozambique tilapia (O. mossambicus) (50 g), only partial compensatory growth was observed after food reestablishment. These fasted juveniles exhibited higher SGR until 6 weeks of refeeding, whereas at the eighth week of refeeding, SGR did not differ from the control, suggesting that compensatory growth was limited to the first 6 weeks of refeeding (Fox et al. 2010).

In our study we evaluated food consumption in the first 3 days of refeeding, but hyperphagia was not noticed. Feed intake/body mass in refed fish increased at $2 \mathrm{WR}$ in the $\mathrm{F} 2$ treatment and at $6 \mathrm{WR}$ and $10 \mathrm{WR}$ in the F3 treatment. At 10WR, feed intake/body mass in fasted fish was higher than it was in control fish by $10.9 \%, 21.6 \%$, and $66.9 \%$ in F1, F2, and F3 respectively. However, the increase in feed intake by refed fish was not enough to improve the feed conversion ratio or to induce the same growth as occurred in control fish. Although compensatory growth has typically been characterized by hyperphagia, improved feed conversion ratio, and elevated SGR (Ali, Nicieza, and Wooton 2003; Picha, Silverstein, and Borski 2006; Won and Borsk 2013), studies have shown that hyperphagia alone can result in relatively low levels of growth compensation (Gurney et al. 2003; Urbinati, Sarmiente, and Takahashi 2014). Our results indicated that only tilapia juveniles subjected to the shortest fasting period ( 1 week, F1) were able to achieve, during refeeding, the same SGR and feed intake levels seen in control fish. However, F1 fish were smaller than control fish and were unable to achieve full compensatory growth.

The survival rate of Nile tilapia juveniles $(30.2 \pm 0.9 \mathrm{~g})$ was not affected by fasting for up to 3 weeks, and survival rate was high at the end of the experiment ( $>84 \%$ in FC, F1, and F2 treatments and approximately $79 \%$ in F3), demonstrating the robustness of the species. However, in smaller Nile 
tilapia (6.6 g) subjected to 4 weeks of fasting with subsequent refeeding for 8 weeks, Wang, Qin, and Han (2009) reported lower survival rates (60\%).

Liver glycogen and body lipid reserves appear to be the main energy sources mobilized by tilapia during fasting to maintain vital processes, as carcass lipid content was significantly reduced in fasted fish during the food restriction periods. In agreement with our results, body lipid levels were significantly lower in juvenile hybrid tilapia (O. niloticus $\mathrm{x}$ O. aureus) deprived of feed for 2 and 3 days per week for 4 months, in comparison to control-fed fish (Abdel-Hakim et al. 2009). In contrast, in Nile tilapia juveniles subjected to different cycles of fasting and refeeding, no differences in carcass lipid content was noticed (Wang, Qin, and Han 2009). However, in this experiment it was observed that carcass lipid increased in all refed fish at the end of the experiment and that it was higher in fish from the F3 treatment than in control fish. The quick restoration of liver glycogen and body lipid reserves in refed fish are indicative of the importance of both reserves in tilapia.

Two to 3 weeks of fasting also decreased visceral fat but did not affect fish muscle protein. The visceral fat index (VFI) of fasted fish after 2 and 3 weeks of fasting was lower than that of control fish. Moreover, the hepatosomatic index (HSI) decreased significantly in all fasted fish in comparison to the control, indicating that the decrease in HSI was likely due to depletion of stored nutrients like fat and glycogen in the liver. Liver weight is immediately affected by fasting, and its reduction has also been observed in other species (Francesco et al. 2004; Peterson and Small 2004; Guroy et al. 2011; Han et al. 2011; Pujante et al. 2014). For instance, sturgeon (Huso huso) is able to conserve carcass protein better than lipid in different schemes of fasting and refeeding (Falahatkar 2012). In the present study, carcass protein and muscle protein in fish from all fasted treatments did not decrease during the experiment. However, in a different study, carcass protein was found to be reduced in Nile tilapia after 4 weeks of fasting (Wang, Qin, and Han 2009). Thus, in our study, tilapia spared muscle protein and carcass protein during fasting by utilizing lipids from the peritoneal cavity as the primary energy source.

In contrast to findings by Abdel-Tawwab et al, in this study we did not detect significant changes in glucose, serum protein, and serum cholesterol levels during the fasting periods. Finding in this study may be related to liver glycogen mobilization, which is known to assist in maintaining blood glucose levels with similar effects on serum protein and cholesterol levels. Likewise, in other fish species, including traira (Hoplias malabaricus, Rios et al. 2006), cod (Gadus morhua, Black and Love 1986), channel catfish (I. punctatus, Gaylord and Gatlin 2000) and sunshine bass (Morone chrysops x Morone saxatilis, Davis and Gaylord 2011), liver glycogen decreased during fasting. 
Nonetheless, after food reestablishment, liver glycogen was completely restored in refed tilapia.

In fish production, the main stressors include food scarcity, high density, poor water quality, low temperature, handling, transport, and acclimation (Barton 2002; Won and Borsk 2013). Particularly in the case of Nile tilapia, conflict associated with the maintenance of dominance relationships can also be a stressor. Stress in fish involves the release of catecholamines (e.g., norepinephrine and epinephrine), glucose, and glucocorticoids such as cortisol, which is the major corticosteroid in teleost fish and the main hormone of catabolism and which can rise during stress situations (Barton 2002; Won and Borsk 2013). In our study, cortisol levels in fasted and refed fish were not significantly higher than in the fed control throughout the experiment. Apparently, the stress response during the experiment was likely more due to handling and reestablishment of the dominance relationship after adjustment of stock density in the tanks than to stress induced by fasting.

In summary, fasting for 1 to 3 weeks with subsequent refeeding for 10 weeks resulted in partial compensatory growth in Nile tilapia juveniles. During fasting, fish primarily mobilize their lipid reserves and hepatic glycogen to maintain vital functions. Muscle and carcass protein do not appear to be mobilized during and after depletion of hepatic and lipid energy reserves, showing that 1 to 3 weeks of fasting were not long enough to induce changes in the relative concentration of muscle protein. It can be concluded that in situations that require complete food restriction in Nile tilapia juveniles (about $30 \mathrm{~g}$ ), an acceptable strategy is to limit the period of fasting to 1 week or less to minimize losses and to achieve partial compensatory growth. However, fish fasted for more than 1 week may need more time to achieve weight equal to nonfasted fish.

\section{Funding}

This work was funded by the Fundação de Amparo à Pesquisa do Estado de São Paulo for student doctoral scholarships (2011/08426-3 and 2013/13100-3) and a research grant (2011/ 22326-0).

\section{References}

Abdel-Hakim, N. F., H. A. Abo-State, A. A. Al-Azab, and K. H. F. El-Kholy. 2009. Effect of feeding regimes on growth performance of juvenile hybrid tilapia (Oreochromis niloticus $\mathrm{x}$ Oreochromis aureus). World Journal of Agricultural Sciences 5:49-54.

Ali, M., A. Nicieza, and R. J. Wooton. 2003. Compensatory growth in fishes: A response to growth depression. Fish and Fisheries 4:147-190. doi:10.1046/j.1467-2979.2003.00120.x.

Antonopoulou, E., E. Kentepozidou, K. Feidantsis, C. Roufidou, S. Despoti, and S. Chatzifotis. 2013. Starvation and re-feeding affect Hsp expression, MAPK activation and antioxidant 
enzymes activity of European sea bass (Dicentrarchus labrax). Comparative Biochemistry and Physiology, Part A 165:79-88. doi:10.1016/j.cbpa.2013.02.019.

Association of Official Analytical Chemists (AOAC). 2000. Official methods of analysis of the Association of Official Analytical Chemists, 15th ed. Washington, DC: Author.

Barton, B. A. 2002. Stress in fishes: A diversity of responses with particular reference to changes in circulating corticosteroids. Integrative and Comparative Biology 42:517-525. doi:10.1093/icb/42.3.517.

Black, D., and R. M. Love. 1986. The sequential mobilisation and restoration of energy reserves in tissues of Atlantic cod during starvation and refeeding. Journal of Comparative Physiology B 156:469-479. doi:10.1007/BF00691032.

Bligh, E. G., and W. J. Dyer. 1959. A rapid method for total lipid extraction and purification. Canadian Journal of Biochemistry and Physiology 37:911-917. doi:10.1139/y59-099.

Bradford, M. 1976. A rapid and sensitive method for the quantification of microgram quantities of protein using the principle of protein dye-binding. Analysis of Biochemistry 72:248-254. doi:10.1016/0003-2697(76)90527-3.

Breves, J. P., C. K. Tipsmark, B. A. Stough, A. P. Seale, B. R. Flack, B. P. Moorman, D. R. Lerner, and E. Gordon Grau. 2014. Nutritional status and growth hormone regulate insulin-like growth factor binding protein (igfbp) transcripts in Mozambique tilapia. General and Comparative Endocrinology 207:66-73. doi:10.1016/j.ygcen.2014.04.034.

Davis, K. B., and T. G. Gaylord. 2011. Effect of fasting on body composition and responses to stress in sunshine bass. Comparative Biochemistry and Physiology A 158:30-36. doi:10.1016/j.cbpa.2010.08.019.

Drew, R. E., K. J. Rodnick, M. Settles, J. Wacyk, E. Churchill, M. S. Powel, R. W. Hardy, G. K. Murdock, R. A. Hill, and B. D. Robison. 2008. Effect of starvation on transcriptomes of brain and liver in adult female zebrafish (Danio rerio). Physiological Genomics 35:283-295. doi:10.1152/physiolgenomics.90213.2008.

Falahatkar, B. 2012. The metabolic effects of feeding and fasting in beluga Huso huso. Marine Environmental Research 82:69-75. doi:10.1016/j.marenvres.2012.09.003.

Fitzsimmons, K., R. Martínez-García, and P. González-Alanis. 2011. Why tilapia is becoming the most important food fish on the planet. In Better science, better fish, better life: Proceedings of the ninth international symposium on tilapia in aquaculture, ed. L. Liu and K. Fitzsimmons, 8-17. Shanghai, China: AquaFish Collaborative Research Support Program.

Food and Agriculture Organization of the United Nations (FAO). 2012. The State of World Fisheries and Aquaculture. http://www.fao.org/docrep/016/i2727e/i2727e00.htm

Fox, B. K., J. P. Breves, L. K. Davis, and A. L. Pierce. 2010. Tissue-specific regulation of the growth hormone/insulin-like growth factor axis during fasting and re-feeding: Importance of muscle expression of IGF-I AND IGF-II mRNA in the tilapia. General and Comparative Endocrinology 166:573-580. doi:10.1016/j.ygcen.2009.11.012.

Francesco, M., G. Parisi, F. Médale, P. Lupi, S. J. Kaushik, and B. M. Poli. 2004. Effect of longterm feeding with a plant protein mixture based diet on growth and body/fillet quality traits of large rainbow trout (Oncorhynchus mykiss). Aquaculture 236:413-429. doi:10.1016/j.aquaculture.2004.01.006.

Gaylord, T. G., and D. M. Gatlin III. 2000. Assessment of compensatory growth in channel catfish Ictalurus punctatus R. and associated changes in body condition indices. Journal of the World Aquaculture Society 31:326-336. doi:10.1111/j.1749-7345.2000.tb00884.x.

Gaylord, T. G., and D. M. Gatlin III. 2001. Dietary protein and energy modifications to maximize compensatory growth of channel catfish (Ictalurus punctatus). Aquaculture 194:337-348. doi:10.1016/S0044-8486(00)00523-8. 
Grigorakis, K., and M. N. Alexis. 2005. Effects of fasting on the meat quality and fat deposition of commercial-size farmed gilhead sea bream (Sparus aurata, L.) fed different dietary regimes. Aquaculture Nutrition 11:341-344. doi:10.1111/j.1365-2095.2005.00351.x.

Gurney, W. S. C., W. Jones, A. R. Veitch, and R. M. Nisbet. 2003. Resource allocation, hyperphagia, and compensatory growth in juveniles. Ecology 34:2777-2787. doi:10.1890/ 02-0536.

Guroy, D., B. Guroy, D. L. Merrifield, S. Ergun, A. A. Tekinay, and M. Yigit. 2011. Effect of dietary Ulva and Spirulina on weight loss and body composition of rainbow trout, Oncorhynchus mykiss (Walbaum) during a starvation period. Journal of Animal Physiology and Animal Nutrition 95:320-327. doi:10.1111/j.1439-0396.2010.01057.x.

Han, C., X. Wen, Q. Zheng, and H. Li. 2011. Effect of starvation on activities and mRNA expression of lipoprotein lipase and hormone-sensitive lipase in tilapia (Oreochromis niloticus x O. areus). Fish Physiology and Biochemistry 37:113-122. doi:10.1007/s10695010-9423-6.

Jobling, M. 1980. Effects of starvation on proximate chemical composition and energy utilization of plaice, Pleuronectes platessa L. Journal of Fish Biology 17:325-334. doi:10.1111/jfb.1980.17.issue-3.

Jobling, M., and J. S. Johansen. 1999. The lipostat, hyperphagia and catch-up growth. Aquaculture Research 30:473-478. doi:10.1046/j.1365-2109.1999.00358.x.

Love, R. M. 1970. The chemical biology of fishes. London: Academic Press.

Moon, T. W., G. D. Foster, and E. M. Plisetskaya. 1989. Changes in peptide hormone and liver enzymes in the rainbow trout deprived of food 6 weeks. Canadian Journal of Zoology 67:2198-2193. doi:10.1139/z89-309.

Navarro, I., and J. Gutiérrez. 1995. Fasting and starvation. In Biochemistry and molecular biology of fishes, ed. P. W. Hochanchka and T. P. Mommsen, 393-434. Amsterdam: Elsevier Science.

Nebo, C., M. Portella, F. Carani, F. Alves De Almeida, C. Padovani, R. Carvalho, and M. DalPai-Silva. 2013. Short periods of fasting followed by refeeding change the expression of muscle growth-related genes in juvenile Nile tilapia (Oreochromis niloticus). Comparative Biochemistry and Physiology, Part B 164:268-274. doi:10.1016/j.cbpb.2013.02.003.

Nicieza, A. G., and D. Álvarez. 2009. Statistical analysis of structural compensatory growth: How can we reduce the rate of false detection? Ecology 159:27-39.

Pérez-Jiménez, A., G. Carcenete, M. C. Hidalgo, A. García-Alcázer, E. Abellán, and A. E. Morales. 2012. Metabolic adjustments of Dentex dentex to prolonged starvation and refeeding. Fish Physiology and Biochemistry 38:1145-1157. doi:10.1007/s10695-011-9600-2.

Peterson, B. C., and B. C. Small. 2004. Effects of fasting on circulating IGF-binding proteins, glucose, and cortisol in channel catfish (Ictalurus punctatus). Domestic Animal Endocrinology 26:231-240. doi:10.1016/j.domaniend.2003.10.005.

Picha, M. E., J. T. Silverstein, and R. J. Borski. 2006. Discordant regulation of hepatic IGF-I mRNA and circulating IGF-I during compensatory growth in a teleost, the hybrid striped bass (Morone chrysops x Morone saxatilis). General and Comparative Endocrinology 134:196-205. doi:10.1016/j.ygcen.2005.12.020.

Pujante, I., J. Martos-Sitcha, F. Moyano, I. Ruiz-Jarabo, G. Martínez-Rodríguez, and J. Mancera. 2014. Starving/re-feeding processes induce metabolic modifications in thicklipped grey mullet (Chelon labrosus, Risso 1827). Comparative Biochemistry and Physiology, Part B 180:57-67. doi:10.1016/j.cbpb.2014.10.005.

Rios, F. S. A., G. Moraes, E. T. Oba, M. N. Fernandes, L. Donatti, A. L. Kalinin, and F. T. Rantin. 2006. Mobilization and recovery of energy in traíra, Hoplias malabaricus Block (Teleostei, Erythrinidae) during long-term starvation and after re-feeding. Journal of Comparative Physiology B 176:721-728. doi:10.1007/s00360-006-0098-3. 
Urbinati, E. C., S. J. Sarmiente, and L. S. Takahashi. 2014. Short-term cycles of feed deprivation and refeeding promote full compensatory growth in the Amazon fish matrinxã (Brycon amazonicus). Aquaculture 433:430-433. doi:10.1016/j.aquaculture.2014.06.030.

Wang, T., C. C. Y. Hung, and D. J. Randal. 2006. The comparative physiology of food deprivation: From feast to famine. Annual Review of Physiology 68:223-251. doi:10.1146/ annurev.physiol.68.040104.105739.

Wang, Y., Y. Cui, Y. Yang, and F. Cai. 2000. Compensatory growth in hybrid tilapia, Oreochromis mossambicus x O. niloticus, reared in seawater. Aquaculture 189:101-108. doi:10.1016/S0044-8486(00)00353-7.

Wang, Y., J. G. Qin, and H. Han. 2009. Cyclical feed deprivation and refeeding fails to enhance compensatory growth in Nile tilapia, Oreochromis niloticus L. Aquaculture 40:204-201. doi:10.1111/j.1365-2109.2008.02083.x.

Won, E. T., and R. J. Borsk. 2013. Endocrine regulation of compensatory growth in fish. Frontiers in Endocrinology 4:74. doi:10.3389/fendo.2013.00074.

Zhang, X. D., Y. F. Zhu, L. S. Cai, and T. X. Wu. 2008. Effects of fasting on the meat quality and antioxidant defenses of market-size farmed large yellow croaker (Pseudosciaena cracea). Aquaculture 280:136-139. doi:10.1016/j.aquaculture.2008.05.010. 